\title{
Covid-19 Interstitial Pneumonia: Histological and Immunohistochemical Features on Cryobiopsies
}

\author{
Claudio Doglioni $^{a}$ Claudia Ravaglia $^{b}$ Marco Chilosi ${ }^{c}$ Giulio Rossi $^{d}$ \\ Alessandra Dubini ${ }^{\mathrm{e}}$ Federica Pedica $^{f}$ Sara Piciucchi ${ }^{g}$ Antonio Vizzuso ${ }^{g}$ \\ Franco Stellah $^{\text {h Stefano Maitan }}{ }^{\text {i }}$ Vanni Agnoletti ${ }^{j}$ Silvia Puglisi $^{\text {b }}$ \\ Giovanni Poletti $^{k}$ Vittorio Sambril, $m$ Giovanni Pizzolo ${ }^{n}$ Vincenzo Bronte ${ }^{\circ}$ \\ Athol U. Wells ${ }^{p}$ Venerino Poletti ${ }^{b, q}$

\begin{abstract}
aDepartment of Pathology, University Vita-Salute, Milan and San Raffaele Scientific Institute, Milan, Italy;
bPulmonology Unit, Thoracic Diseases Department, G.B. Morgagni Hospital, Forlì, Italy; 'Department of Pathology,

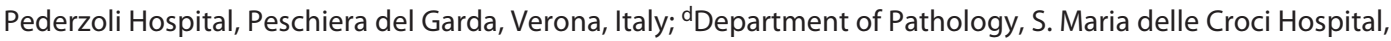

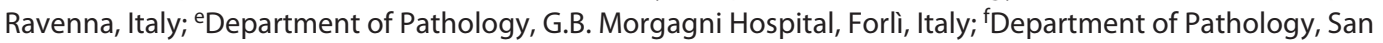
Raffaele Scientific Institute, Milan, Italy; ${ }^{9}$ Department of Radiology, G.B. Morgagni Hospital, Forlì, Italy; ${ }^{\text {h}}$ Alma Mater Studiorum Bologna University, Thoracic Surgery Unit, G.B. Morgagni Hospital, Forlì, Italy; 'Intensive Care Unit, G.B. Morgagni Hospital, Forlì, Italy; ${ }^{j}$ Intensive Care Unit, M. Bufalini Hospital, Cesena, Italy; ${ }^{k}$ Clinical Pathology Unit, The Great Romagna Area Hub Laboratory, Pievesestina, Cesena, Italy; 'Microbiology Unit, The Great Romagna Area Hub Laboratory, Pievesestina, Cesena, Italy; ${ }^{\mathrm{m} D I M E S, ~ B o l o g n a ~ U n i v e r s i t y, ~ B o l o g n a, ~ I t a l y ; ~}{ }^{\mathrm{n} V e r o n a}$ University, Verona, Italy; Immunology Section, Department of Medicine, Verona University Hospital, Verona, Italy; PInterstitial Lung Disease Unit, Royal Brompton Hospital, London, UK; ${ }^{9}$ Department of Respiratory Diseases and Allergy, Aarhus University Hospital, Aarhus, Denmark
\end{abstract}

\section{Keywords}

SARS-CoV-2 · Coronavirus · Covid-19 · Acute respiratory distress syndrome $\cdot$ Lung biopsy · Cryobiopsy · pSTAT-3 . Indoleamine 2,3-dioxygenase-1

\begin{abstract}
Background: The pathogenetic steps leading to Covid-19 interstitial pneumonia remain to be clarified. Most postmortem studies to date reveal diffuse alveolar damage as the most relevant histologic pattern. Antemortem lung biopsy may however provide more precise data regarding the earlier stages of the disease, providing a basis for novel treat-
\end{abstract}

ment approaches. Objectives: To ascertain the morphological and immunohistochemical features of lung samples obtained in patients with moderate Covid-19 pneumonia. Methods: Transbronchial lung cryobiopsy was carried out in 12 Covid-19 patients within 20 days of symptom onset. $\boldsymbol{R e}$ sults: Histopathologic changes included spots of patchy acute lung injury with alveolar type II cell hyperplasia, with no evidence of hyaline membranes. Strong nuclear expression of phosphorylated STAT3 was observed in $>50 \%$ of AECII. Interalveolar capillaries showed enlarged lumen and

Claudio Doglioni and Claudia Ravaglia contributed equally. karger@karger.com www.karger.com/res

(c) 2021 S. Karger AG, Basel

Karger ${ }^{\prime}=$
Claudia Ravaglia

Pulmonology Unit, Thoracic Diseases Department, G.B. Morgagni Hospital Via C. Forlanini 34 IT-47100 Forlì (Italy)

claudiaravaglia79@gmail.com 
were in part arranged in superposed rows. Pulmonary venules were characterized by luminal enlargement, thickened walls, and perivascular $\mathrm{CD}^{+}{ }^{+} \mathrm{T}$-cell infiltration. A strong nuclear expression of phosphorylated STAT3, associated with PD-L1 and IDO expression, was observed in endothelial cells of venules and interstitial capillaries. Alveolar spaces macrophages exhibited a peculiar phenotype (CD68, CD11C, CD14, CD205, CD206, CD123/IL3AR, and PD-L1). Conclusions: Morphologically distinct features were identified in early stages of Covid-19 pneumonia, with epithelial and endothelial cell abnormalities different from either classical interstitial lung diseases or diffuse alveolar damage. Alveolar type II cell hyperplasia was a prominent event in the majority of cases. Inflammatory cells expressed peculiar phenotypes. No evidence of hyaline membranes and endothelial changes characterized by IDO expression might in part explain the compliance and the characteristic pulmonary vasoplegia observed in less-advanced Covid-19 pneumonia.

(c) 2021 S. Karger AG, Basel

\section{Introduction}

Coronavirus disease 2019 (Covid-19) is an infectious disease caused by a novel coronavirus, SARS-CoV-2. Covid-19 infection is characterized by clinical variability, with some patients developing mild symptoms and others rapidly progressing to acute respiratory failure requiring intensive care unit treatment [1]. Despite intense investigation, the pathogenesis of Covid-19 is incompletely understood. The relevance of pathological information has been repeatedly highlighted [2], and a considerable number of systematic postmortem examinations have been published thus far [1-6]. Nevertheless, only a handful of reports of antemortem biopsy findings are currently available $[7,8]$, which limits the knowledge about the early phases of the Covid-19 interstitial pneumonia. In the lung, autopsies of Covid-19 have generally revealed histological features of diffuse alveolar damage (DAD) with hyaline membranes, interstitial and intra-alveolar proteinaceous edema, and type II pneumocyte hyperplasia, consistent with a histopathologic background of acute respiratory distress syndrome [9]. Although most postmortem studies describe the severe Covid-19 pneumonia as "identical" to non-Covid-19 DAD/acute respiratory distress syndrome, the disproportionate occurrence of thromboembolic complications, microangiopathic lesions, and endothelial injury suggest Covid-19-specific features purporting an endothelial-dependent contribution to disease pathogenesis $[3,5,10]$. These observations however clash with the preserved lung compliance documented in a significant number of patients with respiratory failure $[11,12]$ and with the few available data regarding the first phases of interstitial pneumonia, which do not document the typical DAD findings $[7,8]$. Furthermore, no data on either the cellular target of infection or immunohistochemical markers describing the inflammatory infiltrate and signaling pathways have been provided by reports on early-phase pneumonia.

Here, we examine the morphologic and immunomolecular features of a series of patients affected by Covid-19 interstitial pneumonia. Biopsies were carried out in the first 20 days of symptom appearance. This study was performed in accordance with regulations issued by the Helsinki Declaration; the protocol was approved by the Institutional Review Board (IRB) of the Area Vasta Romagna Ethical Committee (Prot. 2672), and patients have provided their informed consent according to the rules applied in our hospital, accepting potential risks and advantages of the proposed procedure (patients were informed that the identification of pulmonary histologic lesions might have helped to drive treatment decisions or drug selection).

\section{Materials and Methods}

Enrolled subjects were aged between 31 and 76 years, with confirmed diagnosis of Covid-19 and high-resolution computed tomography scan analysis showing parenchymal lung involvement. All patients were not in need of invasive ventilatory support. A total severity score was calculated according to Pan et al. [13].

Covid-19 was diagnosed with real-time reverse-transcriptasepolymerase-chain-reaction assay for SARS-CoV-2 in respiratory tract samples tested by a designated hospital diagnostic laboratory. Key exclusion criteria were excessive or uncorrectable bleeding risk and cardiovascular disease with clinically overt heart failure. Lung samples were obtained by transbronchial lung cryobiopsy, using a standardized methodology [14] within 20 days of the first symptom appearance. During the bronchoscopy procedure, bronchoalveolar lavage (BAL) was performed. Lung cryobiopsy samples from 15 patients with diffuse parenchymal lung diseases served as uninfected control specimens: 3 organizing pneumonia (OP), 3 nonspecific interstitial pneumonia (NSIP), 2 OP/NSIP, 2 usual interstitial pneumonia, 2 chronic hypersensitivity pneumonia, 1 acute fibrinous and organizing pneumonia, 1 sarcoidosis, and 1 smoking-related interstitial fibrosis.

Morphologic examination was based on conventional hematoxylin-eosin stains and immunostaining with cytokeratin 7 (CK7). Five expert pulmonary pathologists (A.D., G.R., V.P., M.C., and C.D.) blindly and independently reviewed the slides from all biopsies describing morphological features involving different compartments of lung parenchyma. The presence of SARS-CoV-2 viral genome and IL- 6 was investigated using fluorescence in situ and RNAscope technology with commercially available probes. All 
Table 1. Immunohistochemical and FISH probes utilized in this study

\begin{tabular}{llll}
\hline Antibody & Clone & Source & Cell target \\
\hline CK7 & SP52 & Ventana-Roche & Epithelial cells \\
Ki67 & $30-9$ & Ventana-Roche & AECII \\
Tubulin-beta-3 & TUJ1 & Covance & Myofibroblast-activated AEII \\
CD3 & 2GV6 & Ventana-Roche & T lymphocytes \\
CD4 & SP35 & Ventana-Roche & T cell \\
CD8 & SP57 & Ventana-Roche & T suppressor lymphocytes \\
CD14 & EPR3653 & Ventana-Roche & Macrophages \\
CD20 & L26 & Ventana-Roche & B lymphocytes \\
CD25 & 4C9 & Ventana-Roche & Activated T cells \\
CD30 & Ber-H2 & Ventana-Roche & Activated lymphoid cells \\
CD61 & Vf2 & Ventana-Roche & Platelets and megakariocytes \\
CD123 & LR4M & Leica Biosystems & Plasmacytoid dendritic cells \\
GATA3 & L50-823 & Ventana-Roche & Th2 \\
T-bet & D6N8B & Cell Signaling & Th1 \\
TCF1 & C63F9 & Cell Signaling & T-cell transcription factor \\
MUM1 & MRQ-43 & Ventana-Roche & Plasma cells \\
PD1 & NAT105 & Ventana-Roche & T lymphocytes, subset \\
IDO & D5J4E & Cell Signaling & Immune checkpoint inhibition \\
PD-L1 & 22C3 & Agilent-Dako & Immune checkpoint inhibition \\
Phospho-STAT3 & D3A7 & Cell Signaling & IL-6 pathway \\
SARS-CoV-2 & RNAscope & ACD Biotechne & SARS-CoV-2 virus \\
IL-6 & V-nCoV2019-S & & \\
& RNAscope 2.5 & ACD Biotechne & IL-6 \\
\hline & Probe-Hs-IL-6 C2 & & \\
\hline
\end{tabular}

Table 2. Patients' characteristics and radiographic findings on HRCT

\begin{tabular}{|c|c|c|c|c|c|c|}
\hline 1 & 31 & Male & Fever, cough, fatigue & 8 & 6 & $\begin{array}{l}\text { Ground glass (halo sign), alveolar } \\
\text { consolidation }\end{array}$ \\
\hline 2 & 63 & Male & Fever & 8 & 11 & Pure ground glass, perilobular pattern \\
\hline 3 & 61 & Male & Fever, dyspnea, cough, myalgia, diarrhea & 14 & 4 & Part solid ground glass, perilobular pattern \\
\hline 4 & 76 & Male & Fever, cough, dyspnea & 13 & 11 & Crazy paving, perilobular pattern \\
\hline 7 & 31 & Female & Fever, headache & 6 & 2 & Pure ground glass \\
\hline 8 & 56 & Male & Fever, cough, dyspnea & 20 & 14 & Pure ground glass \\
\hline 9 & 46 & Female & Fatigue, myalgia & 8 & 7 & Part solid ground glass; crazy paving \\
\hline 10 & 50 & Male & Fever & 9 & 13 & Perilobular pattern \\
\hline 11 & 62 & Male & Fever, cough & 14 & 7 & Part solid ground glass; perilobular pattern \\
\hline 12 & 53 & Female & Fever, myalgia, fatigue, diarrhea & 16 & 10 & Perilobular pattern \\
\hline
\end{tabular}

Pt, patient; TSS, total severity score [13]; HRCT, high-resolution computed tomography. * Reported symptoms refer to the time of onset of the disease and/or the time of admission to the hospital. ${ }^{\dagger}$ Enlargement of pulmonary veins (inside and/or outside the areas of ground glass alveolar consolidation) was observed in all cases.

immunohistochemical tests were performed in the ULTRA Benchmark automated immunostainer (Ventana Medical Systems/ Roche, Tucson, AZ, USA) using standard procedures and reagents described in Table 1.

\section{Results}

Clinical characteristics and major radiological and laboratory findings are described in Tables 2 and 3. 
Table 3. Clinical picture and laboratory findings

\begin{tabular}{|c|c|c|c|c|c|c|c|c|}
\hline $\mathrm{Pt}$ & Comorbidities & OT & NIVS* & Treatment at biopsy time $^{\dagger}$ & $\begin{array}{l}\text { Blood } \\
\text { lymphopenia }{ }^{\ddagger}\end{array}$ & $\begin{array}{l}\text { High serum } \\
\text { IL- } 6^{\S}\end{array}$ & $\begin{array}{l}\text { High D-dimer } \\
\text { levels }\end{array}$ & $\begin{array}{l}\text { Increased BAL } \\
\text { lymphocytes** }\end{array}$ \\
\hline 1 & No & No & No & $\begin{array}{l}\text { Hydroxychloroquine } \\
\text { Ritonavir/darunavir } \\
\text { Corticosteroids }\end{array}$ & Yes & No & No & Yes \\
\hline 2 & No & Yes & Yes & $\begin{array}{l}\text { Hydroxychloroquine } \\
\text { Ritonavir/darunavir } \\
\text { Corticosteroids } \\
\text { Enoxaparin }\end{array}$ & Yes & Yes & No & Yes \\
\hline 3 & $\begin{array}{l}\text { Hypertension, } \\
\text { hyperlipidemia, GERD }\end{array}$ & No & No & $\begin{array}{l}\text { Hydroxychloroquine } \\
\text { Corticosteroids } \\
\text { Enoxaparin }\end{array}$ & No & No & No & Yes \\
\hline 4 & Hypertension, obesity, OSA & Yes & Yes & $\begin{array}{l}\text { Hydroxychloroquine } \\
\text { Ritonavir/darunavir } \\
\text { Corticosteroids } \\
\text { Enoxaparin }\end{array}$ & No & No & Yes & No \\
\hline 5 & Hyperlipidemia & No & No & $\begin{array}{l}\text { Hydroxychloroquine } \\
\text { Ritonavir/darunavir } \\
\text { Corticosteroids } \\
\text { Enoxaparin }\end{array}$ & No & No & No & $\mathrm{n} / \mathrm{a}$ \\
\hline 6 & No & Yes & No & $\begin{array}{l}\text { Hydroxychloroquine } \\
\text { Ritonavir/darunavir } \\
\text { Corticosteroids } \\
\text { Enoxaparin }\end{array}$ & No & No & No & No \\
\hline 7 & No & No & No & $\begin{array}{l}\text { Hydroxychloroquine } \\
\text { Ritonavir/darunavir } \\
\text { Corticosteroids }\end{array}$ & No & No & No & Yes \\
\hline 9 & No & No & No & $\begin{array}{l}\text { Corticosteroids } \\
\text { Enoxaparin }\end{array}$ & No & No & Yes & No \\
\hline 10 & Hyperlipidemia & Yes & No & $\begin{array}{l}\text { Corticosteroids } \\
\text { Enoxaparin }\end{array}$ & No & No & Yes & No \\
\hline 11 & No & No & No & $\begin{array}{l}\text { Corticosteroids } \\
\text { Enoxaparin }\end{array}$ & No & $\mathrm{n} / \mathrm{a}$ & Yes & $\mathrm{n} / \mathrm{a}$ \\
\hline 12 & & Psoriasis & No & $\begin{array}{l}\text { Corticosteroids } \\
\text { Enoxaparin }\end{array}$ & No & No & No & $\mathrm{n} / \mathrm{a}$ \\
\hline
\end{tabular}

Pt, patient; OT, oxygen therapy; NIVS; noninvasive ventilator support; BAL, bronchoalveolar lavage; GERD, gastroesophageal reflux disease; OSA, obstructive sleep apnea; $\mathrm{n} / \mathrm{a}$, not available. ${ }^{*}$ All patients did not need invasive ventilation and recovered completely. ${ }^{\dagger}$ All patients received corticosteroids at biopsy time (30-100 mg prednisone equivalent a day); all patients receiving enoxaparin were treated with standard prophylaxis dose. ${ }^{\ddagger}$ Lymphopenia was defined as lymphocytes count $<1.00 \times 10^{9} / \mathrm{L}$ at biopsy time. ${ }^{\S}$ Normal value for serum IL- 6 was $<5.90 \mathrm{pg} / \mathrm{mL}$; significantly high IL-6 levels were defined as IL-6 $>40 \mathrm{pg} / \mathrm{mL}$ at biopsy time. ${ }^{11}$ Cutoff value for D-dimer was $<500 \mu \mathrm{g} / \mathrm{mL}$ FEU. ${ }^{* *}$ BAL lymphocytosis was defined as lymphocytes $>20 \%$. 


\section{Histological Patterns}

Histological evaluation on hematoxylin-eosin-stained slides revealed significant modifications of the pulmonary structure with distortion of the alveolar architecture, AECII hyperplasia, and diffuse vascular modifications. The general pattern did not match, in any case, classical pathological patterns including either subacute OP, acute fibrinous and organizing pneumonia, or acute lung damage (DAD). Type I pneumocyte (AECI) necrosis, alveolar hemorrhage, granulocytic infiltration, and hyaline membranes were absent in all cases, independently from disease timing. In only a few cases, scattered spots of tiny alveolar fibrin buds were detected. Hyperplasia of type II pneumocyte (AECII) was clearly evidenced in 9/12 cases, exhibiting a peculiar "patchy" distribution, ranging from cases with isolated small clusters of AECII to wide prolif- eration of micronodular and/or pseudopapillary sprouts, interposed with variable proportions of morphologically normal AECI; in 3 cases, occasional epithelial syncytial clusters were observed. These findings were more evident in CK7-immunostained slides (shown in Fig. 1). Vascular changes characterized by dilated and hyperplastic interstitial capillaries and venules were present in all cases, including those where AECII hyperplasia was either minimal or absent, as shown in Figure 1. The venules also showed dilatation and tortuosity of the lumen and thickened, edematous walls, without overt vasculitis nor endothelialitis (Fig. 2). Scattered microthrombi were observed in 2 cases. A patchy lymphocyte infiltrate, more prominent around the venules, was observed in 9/12 cases, ranging from isolated to heavy nodular clusters (Fig. 2). Interstitial plasma cells, neutrophils, and eosinophils

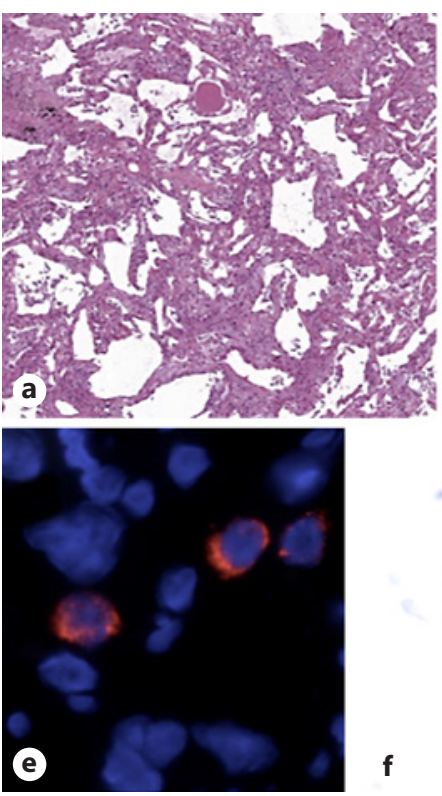

Fig. 1. a, b H\&E: parenchymal structure is variably altered by AECII hyperplasia, vascular enlargement, and interstitial thickening. c, d CK7: AECII form variable small nodules, aggregates, and pseudopapillary sprouts. e In situ demonstration of AECII infected by SARS-CoV-2: cytoplasmic (red) signals are evidenced in scattered cells recognized as AECII by morphology and location. $\mathbf{f}$ In situ

Fig. 2. Abnormal morphology and phenotype in enlarged vascular endothelial cells: H\&E (a); CK7 (b, c). Lymphocyte infiltration of vascular walls: CD3 (d), CD4 (e), and CD8 (f): perivascular lymphocytes mostly exhibit a CD3+, CD4+, CD8-negative immunophenotype. Ph-STAT3 (g): strong nuclear expression in endothelial cells. PD-L1 $(\mathbf{h}, \mathbf{i})$, and IDO $(\mathbf{j})$ : strong expression in capillaries and venules. CD61 (k): occasional positive megakaryocytes within interstitial capillaries. Immunohistochemical profile of aggregates of alveolar mononuclear cells: CK7 negative $(\mathbf{I}), \mathrm{CD} 11 \mathbf{c}+(\mathbf{m})$, $\mathrm{CD} 4+(\mathbf{n}), \mathrm{CD} 14+(\mathbf{o}), \mathrm{CD} 123+(\mathbf{p}), \mathrm{CD} 206+(\mathbf{q}), \mathrm{CD} 303$-negative $(\mathbf{r})$, and PD-L1+ (s). CK7, cytokeratin 7.

(For figure see next page.) analysis of IL-6 mRNA expression: strong signal is evidenced in scattered AECII. g pSTAT3 immunohistochemistry: strong signal demonstrated in most AECII. $\mathbf{h}$ Tubulin-beta-3 immunohistochemistry: strong signal in AECII; interstitial dilated spaces are negative. i Ki67 immunohistochemistry: elevated (>50\%) proliferation in AECII. CK7, cytokeratin 7. 


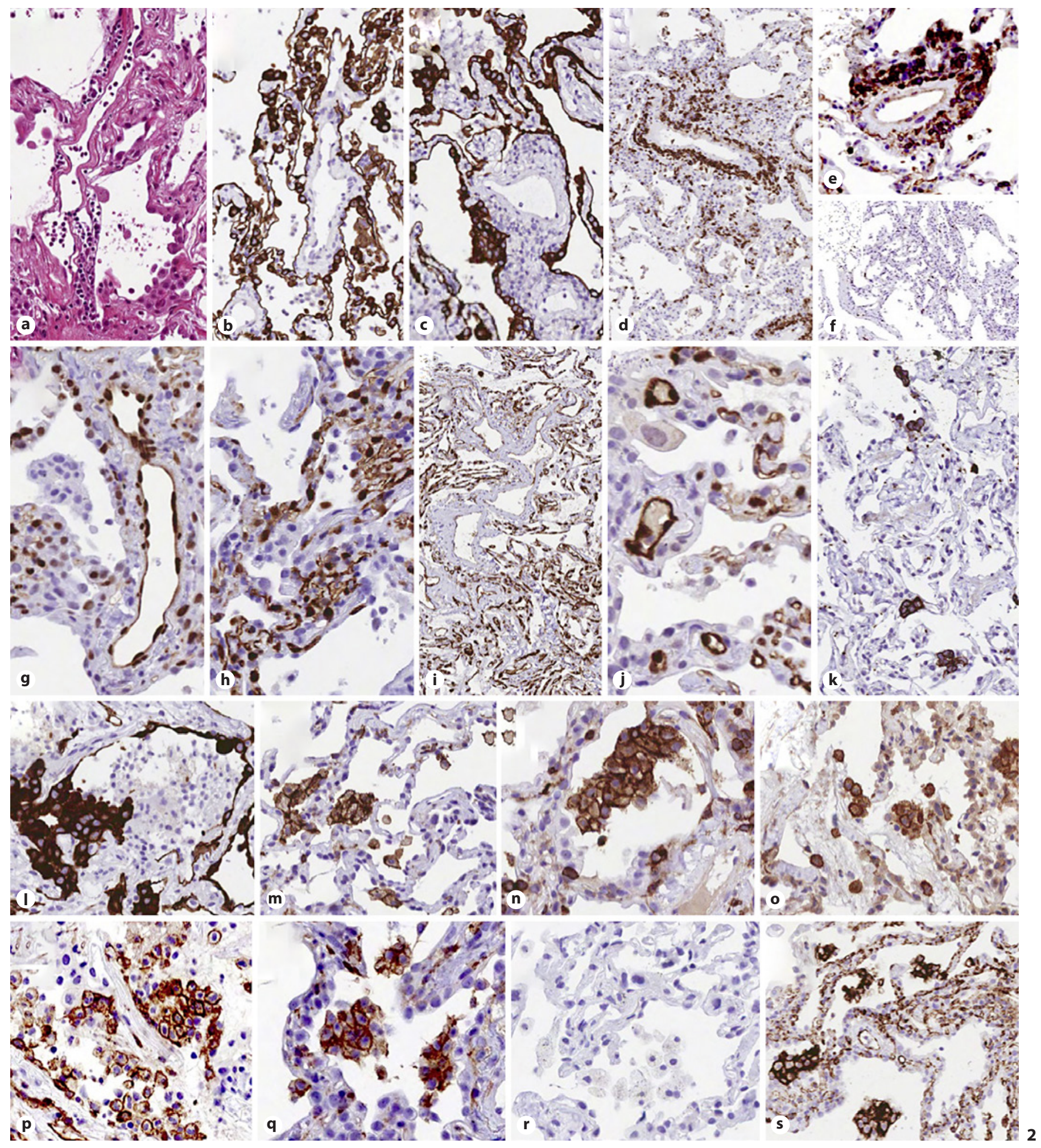


were either absent or extremely rare. Interstitial and luminal organizing changes were absent in all cases, except a single case exhibiting focal myofibroblast accumulation. Irregular clusters of mononuclear cells were demonstrated within alveolar spaces in 9/12 cases, without evidence of intraluminal granulocytes.

\section{In situ Analysis and Immunohistochemistry}

Epithelial Cells

In situ analysis using SARS-CoV-2-specific probes evidenced viral genome in scattered cells recognized as AECII by morphology and distribution (Fig. 1). A semiquantitative evaluation of infected cells showed SARS-CoV2 -positive cells in 10/12 cases, involving from 1 to $10 \%$ of the total AECII population. Similar figures were obtained by in situ analysis using an IL-6-specific probe (Fig. 1). No signal corresponding to infection could be revealed in either endothelial cells or intra-alveolar macrophage clusters. In the AECII sprouts or nodules, the proliferation index, as assessed by Ki67 staining, was $>50 \%$ (Fig. 1 ). Morphologically recognizable apoptotic bodies were not identified, and there was a lack of cleaved caspase- 3 expression. Strong nuclear expression of phosphorylated STAT3 (pSTAT3) was demonstrated in $>50 \%$ AECII in 9/9 investigated cases (Fig. 1). In control cases, pSTAT3 immunoreactivity was either absent or very low, confined to scattered AECII and rare blood vessel. AECII strongly expressed tubulin-beta-3 (a sensitive marker of epithelial mesenchymal transition and activated myofibroblasts), but interstitial spaces were negative (Fig. 1), revealing the rarity/absence of ongoing fibrosis in contrast to typical $\mathrm{DAD}$, where intense staining is invariably located in thickened interstitial spaces [15]. In only one case, focal interstitial tubulin-beta-3 expression was present, localized in areas of myofibroblast infiltration.

\section{Macrophages}

Irregular clusters of mononuclear cells, characterized as macrophages by the CD68+, CD11c+, and CD14+ immunophenotype, were present within alveolar spaces in $10 / 12$ cases. These cells were smaller than typical alveolar macrophages and exhibited, in 3/3 investigated cases, an unusual "hybrid" phenotype including dendritic-cell markers (DC-Lamp/CD208, CD206, and CD123/IL3AR). Myeloperoxidase, CD303, and CD117 negativity excluded the presence of myeloid cells, plasmacytoid dendritic cells, and mastocytes. The pSTAT3 nuclear immunostaining was never observed in these macrophages. Immunohistochemical analysis of immune checkpoint pathways revealed strong expression of PD-L1 in alveolar macrophage clusters, but indoleamine 2,3-dioxygenase-1 (IDO) was negative in all cases (Fig. 2).

Blood Vessels

Although a relevant finding was the increased number of capillaries in the alveolar septa, including 2 cases with minimal AECII hyperplasia, endothelial cells were negative for proliferation cues (i.e., Ki67). Endothelial cells located in the alveolar capillaries and pulmonary venules presented a rather unexpected immunophenotype, which included strong nuclear expression of pSTAT3 in endothelial cells of both venules and interstitial capillaries (Fig. 2) and strong diffuse expression of PD-L1 and IDO, 2 molecules related to the regulation of adaptive immunity (Fig. 2; Table 1) $[16,17]$. These findings appeared to be related to Covid-19 pneumonia in particular, since comparable expression of pSTAT3, PD-L1, and IDO was never observed in control cases where the endothelial expression was faint and/or restricted to rare cells. CD61 highlighted the presence of isolated megakariocytes entrapped within interstitial capillaries (3/12 cases) and scattered microthrombi in 2/12 cases (Fig. 2).

\section{Lymphoid Infiltrate}

A thorough immunophenotypic analysis of infiltrating lymphocytes demonstrated that they were invariably represented by $\mathrm{CD} 3+, \mathrm{CD} 8$ - cells (Fig. 2). A more extended analysis could be performed in 3 cases, showing negativity for functional and activation markers T-bet, FOXP3, PD1, CD25, and CD30. Only the Th2-related marker GATA3 [18] was expressed by a minority of perivascular lymphocytes in $2 / 3$ cases (10-20\%). Small collections of interstitial CD8+, $\mathrm{PD}-1+$, and TCF1+ lymphocytes were occasionally observed in interstitial spaces. In all cases, CD56+ NK cells, CD20+ B cells, and MUM1+ plasma cells were either extremely rare or absent.

\section{Discussion}

The most relevant findings of this study can be summarized as follows. The morphological changes do not match with the typical features of DAD observed on a large number of postmortem studies $[4,5,9,19,20]$. The absence of hyaline membranes is particularly relevant, confirming the observations of all antemortem perioperative reports $[7,8]$. Another observation is the absence or rarity of myofibroblast accumulation in the interstitial spaces, a finding confirmed immunohistochemically by the lack of tubulin-beta-3 expression (Fig. 1) [15]. The 
only relevant feature documenting the occurrence of acute lung injury was the proliferation of AECII. These cells, in most cases (10/12) of our series, were arranged in nodules or pseudopapillary sprouts with a peculiar patchy distribution, better emphasized by CK7 immunostaining. This atypical AECII hyperplasia, occurring in all samples with variable grades, was associated with relevant pathological changes in the vascular component, characterized in all cases by hyperplasia of alveolar capillaries with dilated lumens, as well as dilated and tortuous postcapillary venules (Fig. 2).

The in situ hybridization demonstrated the presence of viral genome in cells with morphology and location consistent with AECII (Fig. 1), in agreement with the prevalent angiotensin converting enzyme- 2 expression in these cells [21]. Infected epithelial cells were scattered among the majority of FISH or RNA-scope-negative AECII, suggesting that infection of a small number of epithelial cells may be sufficient to trigger the pathologic process by a paracrine effect. IL-6 is a stimulator of STAT3 and NF-kB pathways, and SARS-CoV-2 might be then able to fuel an IL-6 amplifier mechanism in a positive feedback loop [22] . Elevated expression of pSTAT3 in both AECII and endothelial cells in both capillaries and venules (Fig. 2) was also evident and could have a role in disease progression [23]. This finding seems to be characteristic, as comparable levels of pSTAT3 expression were never observed in control samples including cases of non-Covid-19 DAD and cases of OP and NSIP. Imbalanced activation of the NF-kB/ STAT3 pathway is generally ascribed to innate immune response following infection [24], but the data collected by this study suggest a different scenario, whereby the initial local triggering by parenchymal cells might significantly amplify this mechanism. As for other STATs, this powerful and pleiotropic pathway is able to support mechanisms involved in cell proliferation, survival, and angiogenesis [25]. In line with this hypothetical scheme, AECII in early interstitial Covid-19 pneumonia cases do not exhibit apoptotic markers (morphology and expression of caspase-3) and show an elevated proliferation index $(>50 \% \mathrm{Ki} 67+)$. STAT3 has been suggested as a druggable target in Covid-19 [22], and revealing its triggering in the early phase might help to improve the timing of the use of STAT3 inhibitors. The preliminary conclusion drawn by our findings is that the viral infection directly affects AECII that acquire an important role in triggering IL-6STAT3 activation and amplification in Covid-19 interstitial pneumonia, as suggested by the experimental demonstration of a rapid inflammatory response elicited by SARS-CoV-2-infected human AECII [26].

Pathology and Pathogenesis of Early

Covid-19 from Cryobiopsy
A third intriguing finding of the study relates to morphological and immunohistochemical vascular changes. The number and the luminal size of interstitial capillaries and postcapillary venules were consistently increased in all cases. Vascular dysfunction is considered a relevant pathogenic component in the disease severity, likely involved in the cascade of coagulation abnormalities eventually leading to thromboembolic complications in severely ill patients [27]. In a recent study, distinctive vascular abnormalities were demonstrated at autopsy, including severe endothelial injury, intussusceptive neoangiogenesis, microthrombi, and microangiopathy [3]. We demonstrated that vascular abnormalities (disordered angiogenesis with luminal enlargement and dilated vessel wall and perivascular T-cell infiltration) are distinctly present even in moderate Covid-19 interstitial pneumonia.

Another remarkable finding is the demonstration of diffuse and strong expression of PD-L1 and IDO in endothelial cells of both interstitial capillaries and venules, either minimal or absent in control samples. The coregulatory ligand PD-L1 and the tolerogenic enzyme IDO are part of negative feedback circuits that restrain immune responses and maintain peripheral tolerance and are both involved in immune escape of tumors from immune attack $[28,29]$. In addition, experimental evidence has been provided for a role of IDO in inhibiting the production of type I interferon and viral clearance [30]. The endothelial expression of IDO is normally very low or absent in lung tissue [28], but increased after viral infection, likely in response to IFN- $\gamma$ produced by activated lymphocytes [31]. IFN- $\gamma$-induced IDO can represent a defense against intracellular pathogens [32]. Thus, tolerogenic mechanisms previously ascribed to suppressive signals from innate immune responses in Covid-19 [33] might be amplified within the pulmonary microenvironment by endothelial expression of PD-L1 and IDO [34]. Interestingly, PD-L1 expression is enhanced by the IFN- $\gamma$-JAK1/JAK2-STAT1/ STAT2/STAT3-IRF1 axis [35], and both PD-L1 and IDO are implicated in defense mechanisms from lung injury $[36,37]$. It must be pointed out, however, that IDO is also involved in the regulation of vascular perfusion, remodeling, and relaxation and exerts a protective role against human eclampsia and pulmonary hypertension $[16,38$, 39]. Acting as a nitrite reductase, IDO can generate NO under anaerobic conditions [40]. These hemodynamic activities might allow to argue that, when hyperexpressed, IDO controls the pathologically low pulmonary vascular resistance occurring in moderate Covid-19 interstitial pneumonia, providing a biologic background to physio- 
pathology and clinical evidence [11, 41]. These changes might, at least in part, also explain some CT features observed in patients with Covid-19 pneumonia: midfield and distal pulmonary vein dilatation and tortuosity, predominantly within or surrounding areas of lung opacities $[42,43]$. The pulmonary vascular changes possibly sustained by endothelial IDO expression might elucidate the significant hypoxemia (due to ventilatory/perfusion mismatching and "shunt effect") [41] in a parenchyma where alveolar stability is preserved, as suggested by pathophysiological studies and supported by the absence of hyaline membranes [11, 12].

An intra-alveolar cell population expressing macrophage markers (CD68, CD14, and CD11c) with unusual morphology and phenotype (i.e., positive for CD123, CD208, CD206, and PD-L1) was also detected in early lesions. Interestingly, similar phenotypes can be induced in monocytes by pulmonary epithelial cells, determining proinflammatory cytokine production [44]. Depletion of tissue-resident alveolar macrophages with a concomitant increase in monocyte-derived inflammatory macrophages has been demonstrated in Covid-19 patients, as well as the potential pathogenic role of monocytes with immune suppressive activity; the occurrence of these macrophages within the alveolar microenvironment may be related to the defective immune responses in early phases of the disease $[45,46]$. It is possible to argue that the immune-inhibitory signals (PD-L1 and IDO) provided by endothelial cells and intra-alveolar macrophages might result in a further derangement of the antiviral response within the alveolar microenvironment $[33,47]$.

Lymphocytic infiltrate consisting of CD3+CD4+ Tlymphocytes was more prominent around the wall of the venules. These lymphocytes do not exhibit clear functional polarization as evidenced by lack of the transcriptional regulators T-bet, FOXP3, and GATA3 expression [48]. The lymphocytic perivascular infiltration is mirrored in BAL fluids; in fact, half of the patients in this cohort exhibited BAL lymphocytosis $>20 \%$ (Table 3 ). The frequent lymphocytopenia characterizing Covid-19 patients might thus be caused by different mechanisms involving different T-cell subsets: redistribution to the lung may be relevant for $\mathrm{CD}^{+}$cells, whereas cytokine-triggered apoptosis and exhaustion be prevalent for $\mathrm{CD}^{+}$lymphocytes [49].

Limitation of the study is that transbronchial cryobiopsies were carried out in patients with a moderate form of Covid-19 interstitial pneumonia with an average highresolution computed tomography total severity score of
8.5 (range 2-14). No patient progressed to respiratory failure needing invasive ventilatory supports. This could represent a bias due to the small number of cases recruited, the younger age of the patients (average age 54 years), or even to the use of methyl prednisolone, a therapeutic protocol applied in our center even before the publication of the RECOVERY trial results [50]. Additional observations are necessary to define the morphomolecular evolution to the more severe interstitial pneumonia leading to ICU or death.

In conclusion, this study provides unprecedented insights into a missing link between the lung alterations and the systemic immune responses in moderate Covid-19 interstitial pneumonia, showing a complex scenario where severe derangement of the cross-talk between innate and adaptive immune mechanisms are triggered by the viral infection. Tolerogenic and proinflammatory signals are produced quite early in the lung by an array of different cell types, including infected AECII, endothelial cells, and specialized monocytes/macrophages. The balance between the beneficial and detrimental roles of these factors may be crucial for the disease evolution toward either recovery or more severe phases, when oxygen support and ICU become necessary. The close similarity with cancer-related immune impairment can suggest that therapies reverting these altered regulatory circuits might be beneficial also in SARS-CoV-2 pneumonia [48].

\section{Acknowledgements}

We thank Fondazione Cariverona (ENACT Project) for the financial support and AMMP (Associazione Morgagni Malattie Polmonari) for the continuous support.

\section{Statement of Ethics}

This study was performed in accordance with regulations issued by the Helsinki Declaration; the protocol was approved by the Institutional Review Board (IRB) of the Area Vasta Romagna Ethical Committee (Prot. 2672), and patients have provided their informed consent, accepting potential risks and advantages of the proposed procedure.

\section{Conflict of Interest Statement}

The authors have no conflicts of interest to declare related to this manuscript. 


\section{Funding Sources}

No funds have been received for this study.

\section{Author Contributions}

C.D., C.R., M.C., and V.P. conceived of and designed the study; C.D., C.R., M.C., and V.P. wrote the manuscript; C.D., C.R., M.C., G.R., A.D., F.P., S.P., A.U.W., and V.P. contributed to data interpretation; all authors took part in analyzing the data raising hypotheses, commented on drafts of the manuscript, and contributed to writing of the final version of the manuscript.

\section{References}

1 Zhou F, Yu T, Du R, Fan G, Liu Y, Liu Z, et al. Clinical course and risk factors for mortality of adult inpatients with COVID-19 in Wuhan, China: a retrospective cohort study. Lancet. 2020;395(10229):1054-62. Erratum in: Lancet 2020;395(10229):1038.

2 Barth RF, Xu X, Buja LM. A call to action: the need for autopsies to determine the full extent of organ involvement associated with COVID-19. Chest. 2020 Jul;158(1):43-4.

3 Ackermann M, Verleden SE, Kuehnel M, Haverich A, Welte T, Laenger F, et al. Pulmonary vascular endothelialitis, thrombosis, and angiogenesis in Covid-19. N Engl J Med. 2020.

$4 \mathrm{Xu} \mathrm{Z}$, Shi L, Wang Y, Zhang J, Huang L, Zhang C, et al. Pathological findings of COVID-19 associated with acute respiratory distress syndrome. Lancet Respir Med. 2020; $8(4): 420-2$.

5 Menter T, Haslbauer JD, Nienhold R, Savic S, Hopfer H, Deigendesch N, et al. Post-mortem examination of COVID19 patients reveals diffuse alveolar damage with severe capillary congestion and variegated findings of lungs and other organs suggesting vascular dysfunction. Histopathology. 2020.

6 Maiese A, Manetti AC, La Russa R, Di Paolo $\mathrm{M}$, Turillazzi E, Frati P, et al. Autopsy findings in COVID-19-related deaths: a literature review. Forensic Sci Med Pathol. 2020 Oct 7: $1-18$.

7 Zeng Z, Xu L, Xie XY, Yan HL, Xie BJ, Xu WZ, et al. Pulmonary pathology of early-phase COVID-19 pneumonia in a patient with a benign lung lesion. Histopathology. 2020 Nov; 77(5):823-31.

8 Cai Y, Hao Z, Gao Y, Ping W, Wang Q, Peng S, et al. Coronavirus disease 2019 in the perioperative period of lung resection: a brief report from a single thoracic surgery department in Wuhan, People's Republic of China. J Thorac Oncol. 2020;15(6):10651072.

9 Katzenstein and Askin's surgical pathology of non-neoplastic lung disease. 4th ed Philadelphia: Saunders Elsvier; 2006. pp. 17-24.

10 Rovas A, Osiaevi I, Buscher K, Sackarnd J, Tepasse PR, Fobker M, et al. Microvascular dysfunction in COVID-19: the MYSTIC study. Angiogenesis; 2020 Oct 14.

11 Gattinoni L, Chiumello D, Caironi P, Busana M, Romitti F, Brazzi L, et al. COVID-19 pneumonia: different respiratory treatments for different phenotypes? Intensive Care Med. 2020;46(6):1099-102.
12 Grasselli G, Tonetti T, Protti A, Langer T, Girardis M, Bellani G, et al. Pathophysiology of COVID-19 associated acute respiratory distress syndrome: a multicenter prospective observational study. Lancet Respir Med. 2020 Aug 27;S2213-2600(20):30370-2.

13 Pan F, Ye T, Sun P, Gui S, Liang B, Li L, et al. Time course of lung changes on chest CT during recovery from 2019 novel coronavirus (COVID-19) pneumonia. Radiology. 2020; 295:715-21.

14 Ravaglia C, Wells AU, Tomassetti S, Gurioli C, Gurioli C, Dubini A, et al. Diagnostic yield and risk/benefit analysis of trans-bronchial lung cryobiopsy in diffuse parenchymal lung diseases: a large cohort of 699 patients. BMC Pulm Med. 2019;19(1):16.

15 Chilosi M, Caliò A, Rossi A, Gilioli E, Pedica F, Montagna L, et al. Epithelial to mesenchymal transition-related proteins ZEB1, $\beta$-catenin, and $\beta$-tubulin-III in idiopathic pulmonary fibrosis. Mod Pathol. 2017;30(1):2638.

16 Andersen MH. The balance players of the adaptive immune system. Cancer Res. 2018 Mar 15;78(6):1379-82.

17 Yeung AW, Terentis AC, King NJ, Thomas SR. Role of indoleamine 2,3-dioxygenase in health and disease. Clin Sci. 2015 Oct;129(7): 601-72.

18 Zheng WP, Flavell RA. Pillars article: the transcription factor GATA-3 is necessary and sufficient for Th2 cytokine gene expression in CD4 T cells. Cell 1997. 89: 587-596. J Immunol. 2016;196:4426-44.

19 Hariri LP, North CM, Shih AR, Israel RA, Maley JH, Villalba JA, et al. Lung histopathology in coronavirus disease 2019 as compared with severe acute respiratory syndrome and H1N1 influenza: a systematic review. Chest. 2020 Oct 7;S0012-3692(20):34868-6.

20 Udi J, Lang CN, Zotzmann V, Krueger K, Fluegler A, Bamberg F, et al. Incidence of barotrauma in patients with COVID-19 pneumonia during prolonged invasive mechanical ventilation: a case-control study. J Intensive Care Med. 2020 Sept 22: 885066620954364.

21 Zhang H, Penninger JM, Li Y, Zhong N, Slutsky AS. Angiotensin-converting enzyme 2 (ACE2) as a SARS-CoV-2 receptor: molecular mechanisms and potential therapeutic target. Intensive Care Med. 2020;46(4):586-90.
22 Hirano T, Murakami M. COVID-19: a new virus, but a familiar receptor and cytokine release syndrome. Immunity. 2020;52(5):731-3.

23 Matsuyama T, Kubli SP, Yoshinaga SK, Pfeffer K, Mak TW. An aberrant STAT pathway is central to COVID-19. Cell Death Differ. 2020 Oct 9;27(12):3209-25.

24 Blanco-Melo D, Nilsson-Payant BE, Liu WC, Uhl S, Hoagland D, Møller R, et al. Imbalanced host response to SARS-CoV-2 drives development of COVID-19. Cell. 2020; 181(5):1036-e9.

25 Alvarez JV, Frank DA. Genome-wide analysis of STAT target genes: elucidating the mechanism of STAT-mediated oncogenesis. Cancer Biol Ther. 2004 Nov;3(11):1045.

26 Huang J, Hume AJ, Abo KM, Werder RB, Villacorta-Martin $\mathrm{C}$, Alysandratos $\mathrm{KD}$, et al. SARS-CoV-2 infection of pluripotent stem cell-derived human lung alveolar type 2 cells elicits a rapid epithelial-intrinsic inflammatory response. Cell Stem Cell. 2020 Sept 18; S1934-5909(20):30459-8.

27 Teuwen LA, Geldhof V, Pasut A, Carmeliet P. COVID-19: the vasculature unleashed. Nat Rev Immunol. 2020 Jul;20(7):389-91.

28 Meireson A, Devos M, Brochez L. IDO expression in cancer: different compartment, different functionality? Front Immunol. 2020 Sept 24;11:531491.

29 Tumeh PC, Harview CL, Yearley JH, Shintaku IP, Taylor EJ, Robert L, et al. PD-1 blockade induces responses by inhibiting adaptive immune resistance. Nature. 2014;515(7528): 568-71.

30 Hoshi M, Saito K, Hara A, Taguchi A, Ohtaki $\mathrm{H}$, Tanaka R, et al. The absence of IDO upregulates type I IFN production, resulting in suppression of viral replication in the retrovirus-infected mouse. J Immunol. 2010 Sept 15; 185(6):3305-12.

31 Bonavente FM, Soto JA, Pizarro-Ortega MS Bohmwald K, Gonzalez PA, Bueno SM, et al. Contribution of IDO to human respiratory syncytial virus infection. J Leukoc Biol. 2019; 106:933-42.

32 Yoshida R, Urade Y, Tokuda M, Hayaishi O. Induction of indoleamine 2,3-dioxygenase in mouse lung during virus infection. Proc Natl Acad Sci U S A. 1979 Aug;76(8):4084-6.

33 Jeannet R, Daix T, Formento R, Feuillard J, François B. Severe COVID-19 is associated with deep and sustained multifaceted cellular immunosuppression. Intensive Care Med. 2020;46:1769-71. 
34 Taguchi K, Onoe T, Yoshida T, Yamashita Y, Tanaka Y, Ohdan H. Tumor endothelial cellmediated antigen-specific T-cell suppression via the PD-1/PD-L1 pathway. Mol Cancer Res. 2020 Sept;18(9):1427-40.

35 Garcia-Diaz A, Shin DS, Moreno BH, Saco J, Escuin-Ordinas H, Rodriguez GA, et al. Interferon receptor signaling pathways regulating PD-L1 and PD-L2 expression. Cell Rep. 2017; 19(6):1189-201. Erratum in: Cell Rep. 2019; 29:3766.

36 Liu H, Liu L, Visner GA. Nonviral gene delivery with indoleamine 2,3-dioxygenase targeting pulmonary endothelium protects against ischemia-reperfusion injury. Am J Transplant. 2007;7(10):2291-300.

37 Xu S, Yang Q, Bai J, Tao T, Tang L, Chen Y, et al. Blockade of endothelial, but not epithelial, cell expression of PD-L1 following severe shock attenuates the development of indirect acute lung injury in mice. Am J Physiol Lung Cell Mol Physiol. 2020 Apr 1;318(4):L801-12.

38 Wang Y, Liu H, McKenzie G, Witting PK, Stasch JP, Hahn M, et al. Kynurenine is an endothelium-derived relaxing factor produced during inflammation. Nat Med. 2010; 16(3):279-85.
39 Xiao Y, Christou H, Liu L, Visner G, Mitsialis SA, Kourembanas S, et al. Endothelial indoleamine 2,3-dioxygenase protects against development of pulmonary hypertension. Am J Respir Crit Care Med. 2013;188(4):482-91.

40 Lim YJ, Foo TC, Yeung AWS, Tu X, Ma Y, Hawkins CL, et al. Human indoleamine 2,3-dioxygenase 1 is an efficient mammalian nitrite reductase. Biochemistry. 2019 Feb 19; 58(7):974-86.

41 Gattinoni L, Coppola S, Cressoni M, Busana M, Rossi S, Chiumello D. COVID-19 does not lead to a "typical" acute respiratory distress syndrome. Am J Respir Crit Care Med. 2020; 201(10):1299-300.

42 Lang M, Som A, Mendoza DP, Flores EJ, Reid $\mathrm{N}$, Carey D, et al. Hypoxaemia related to COVID-19: vascular and perfusion abnormalities on dual-energy CT. Lancet Infect Dis. 2020;S1473-3099(20):30367-4.

43 Piciucchi S, Ravaglia C, Vizzuso A, Bertocco M, Poletti V. Reversibility of venous dilatation and parenchymal changes density in Sars-Cov-2 pneumonia: toward the definition of a peculiar pattern. Pulmonology. 2020. in press.

44 Gazdhar A, Blank F, Cesson V, Lovis A, Aubert JD, Lazor R, et al. Human bronchial epithelial cells induce CD141/CD123/DC-SIGN/FLT3 monocytes that promote allogeneic Th17 differentiation. Front Immunol. 2017;8:447.
45 Agrati C, Sacchi A, Bordoni V, Cimini E, Notari S, Grassi G, et al. Expansion of myeloidderived suppressor cells in patients with severe coronavirus disease (COVID-19). Cell Death Differ. 2020 Nov;27(11):3196-207.

46 Merad M, Martin JC. Pathological inflammation in patients with COVID-19: a key role for monocytes and macrophages. Nat Rev Immunol. 2020 Jun;20(6):355-62.

47 Gatto L, Franceschi E, Nunno VD, Brandes AA. Potential protective and therapeutic role of immune checkpoint inhibitors against viral infections and COVID-19. Immunotherapy. 2020 Oct;12(15):1111-4

48 Gagliani N, Huber S. Basic aspects of T helper cell differentiation. Methods Mol Biol. 2017; 1514:19-30.

49 Diao B, Wang C, Tan Y, Chen X, Liu Y, Ning $\mathrm{L}$, et al. Reduction and functional exhaustion of $\mathrm{T}$ cells in patients with coronavirus disease 2019 (COVID-19). Front Immunol. 2020;11: 827

50 RECOVERY Collaborative Group, Horby P, Lim WS, Emberson JR, Mafham M, Bell JL, Linsell L, et al. Dexamethasone in hospitalized patients with Covid-19-preliminary report. New Engl J Med. 2020 Jul. 